\title{
The Snake Bites Its Tail: Cyclic Processes in Brahms's Third String Quartet, op. 67
}

WALTER FRISCH

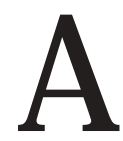

Ithough there is a fair amount of scholarly and analytical literature on Brahms's first two string quartets, op. 51, the remarkable Third Quartet, op. 67 in $B b$, has been unaccountably neglected. ${ }^{1}$ I ts witty, mercurial neo-classical style, especially in the outer movements, places it somewhat apart from the other two quartets and from many mature works of Brahms. It seems appropriate to present this essay in memory of John Daverio. Although Brahms's Bb Quartet was not a work about which John wrote specifically, the issues raised by a close consideration of it are ones with which he was continuously and deeply involved. In almost all his scholarship John was concerned with exploring and teasing out the relationships between the structural and expressive dimensions in great works of the Classical and Romantic repertory. ${ }^{2}$

The idea or practice of cyclic form has been around in one way or another for at least a thousand years in the Western musical tradition, as well as in many non-Western repertories. In most cases, cyclic form is

1 The single modern study of the $\mathrm{B} b$ Quartet of which I am aware is Friedhelm Krummacher, "Von 'allerlei Delikatessen': Ü berlegungen zum Streichquartett op. 67," in Johannes Brahms: Quellen-Text-Rezeption - Interpretation: Internationaler Brahms-K ongress, Hamburg 1997, ed. Friedhelm Krummacher and Michael Struck (Munich: G. Henle, 1999), 127-41.

2 The present essay was originally given as a talk in the context of a workshop and series of master classes supervised by members of the Emerson String Quartet at the State University of New York at Stony Brook in June 2004.

The Journal of M usicology, Vol. 22, Issue 1, pp. 154-172, ISSN 0277-9269, electronic ISSN 1533-8347. (c) 2005 by the Regents of the University of California. All rights reserved. Please direct all requests for permission to photocopy or reproduce article content through the University of California Press's Rights and Permissions website, at http:// www.ucpress.edu/ journals/ rights.htm. 
treated by commentators as a musical structure, whether in one or many sections, which attains coherence at least in part by the recurrence of materials at significant moments. In his New Grove entry on "cyclic form," Hugh Macdonald observes that in its "strictest" meaning the term implies that thematic material returns at the end of a work "to the point whence it set out at the beginning." Macdonald also says that more generally "the term 'cyclic' describes those works where thematic links bind more than one movement; it is not properly applied to mere thematic resemblances." 3 Of course, propriety is hard to establish in such contexts; one analyst's "mere thematic resemblance" may be another's "thematic link."

The creation of thematic unity, or at least coherence, across a musical work became an ever stronger compositional impulse in 18th- and 19 th-century European art music. In the minds of many critics, it also became a criterion for aesthetic value. There seems little question that the efflorescence of cyclic form in the romantic era coincided with the estimation of instrumental music as the highest form of music, and with the concomitant value placed on absolute music, music that was believed to be autonomous and free from any external reference. In absolute music, which lacked text and overt narrative, the reappearance and transformation of thematic material at certain key moments could lend structural cohesion to a work.

Probably the first instance-at any rate, the most famous early one - of a critic noting and admiring something like cyclic form was E. T. A. Hoffmann in his 1810 review of Beethoven's Fifth Symphony. He observes that in the Fifth Symphony "it is particularly the intimate relationship of the individual themes to one other which produces the unity that firmly maintains a single feeling in the listener's heart."4 The kind of thematic coherence $\mathrm{H}$ offmann describes would correspond to Macdonald's notion of thematic links binding different movements, not to the "stricter" sense of cyclic form. In fact, H offmann does not make much in his review of the one genuinely cyclic moment in the symphony: the return of the scherzo at the end of the development section of the finale. Hoffmann seems more interested in aspects of thematic unity.

3 Hugh Macdonald, "Cyclic form," in New Grove Dictionary of Music and Musicians, 2nd ed. (New York: Grove's Dictionaries, 2000). For a helpful but limited summary of historians' and analysts' ideas about cyclic form from the 18th through the 20th centuries, see James Webster, H aydn's "Farewell" Symphony and the Idea of Classical Style (Cambridge: Cambridge Univ., 1991), 179-82.

4 E. T. A. Hoffmann, "Review of Beethoven's Fifth Symphony", Allgemene musikalische Zeitung 12 (4 and 11 July 1810), cols. 630-42,652-59; repr. and trans. in Beethoven: Symphony N 0. 5 in C M inor, Norton Critical Scores, ed. Elliot Forbes (New York: Norton, 1971), 163. 


\section{thejournal of musicology}

Beethoven, however, was clearly intrigued by cyclic principles, and would experiment further with them in late works, especially the Piano Sonata in A, op. 101, the Cello Sonata in C, op. 102, no. 1, and the Ninth Symphony; in each, a later movement or interlude will directly recall an earlier theme. In these cases, the recurrences occur not at the very end of the work, but usually just before the finale. They thus serve neither to round off the piece nor to settle it at a point of origin. Rather, as Elaine Sisman has noted, these recollections are part of a complex process involving memory and fantasy, in which the composer seems to be groping for the proper continuation, the "right place" toward which the work should proceed. ${ }^{5}$ Once that path is found, the recollections are normally set aside or overcome: Beethoven proceeds with an energetic, often triumphant finale. From this point on, there is no looking back.

At the other end of the 19th century, French composers of the circle around Cesar Franck, carried the principe cyclique to new extremes. Saint-Saens' Third Symphony, Franck's D Minor Symphony, and D'Indy's Second Symphony are all intricately cyclic; they are as impressively centralized as any French governmental institution. In Franck's Symphony, the memorable opening three-note chromatic motive reappears at the end of the first movement, and then again at the end of the finale. The slow movement theme also reappears in the finale at important moments.

Brahms falls well between the extremes of Beethoven's "unity" and the French principe cyclique. $\mathrm{H}$ is very earliest works, the three piano sonatas composed between 1851 and 1854, show strong cyclic inclinations. These tend less toward direct thematic recollection than toward thematic transformation. In thematic transformation, a favorite device of Romantic composers like Schubert, Berlioz, and Liszt, a theme will retain its basic contours, but will be altered in mood and affect. The result is like a dramatic change of costume for a character, who still remains recognizably him- or herself. In Brahms's Piano Sonata, op. 1, the main theme of the first movement, grandiose and stately in a broad duple meter-and as such thoroughly appropriate to initiate an op. 1becomes transformed in the finale into a fleet, athletic theme in $\mathbf{9}$. Other parts of the rondo finale refer directly back to the first movement. The third episode, in A minor, for example, is interrupted at

5 Elaine Sisman, "Memory and Invention at the Threshold of Beethoven's Late Style," in Beethoven and $\mathrm{H}$ is World, ed. Scott Burnham and Michael P. Steinberg (Princeton: Princeton Univ. Press, 2000), 51-87. 
measure 125 by a recollection of one of the secondary themes (also originally in A minor) from the exposition of the Allegro (m. 39). ${ }^{6}$

It is the circumstances surrounding this piano sonata that give rise to the title of my essay. In 1894, when he had decided to stop composing new works and before he encountered the clarinetist Richard Mühlfeld, Brahms published his set of 49 folk song arrangements, in which the final selection is "Verstohlen geht der Mond auf," the same song which he had used as the basis of the theme and variations in the second movement of his op. 1 Piano Sonata some 40 years earlier. Brahms wrote to his publisher Simrock, "H as it struck you that I have clearly said my farewell as a composer? The last of the folk-songs and the same one in my O pus 1 represents the snake that bites its tail-and thus states with pretty symbolism that the tale is finished."7 Brahms thus seems to view his own career as a kind of cyclic process, returning to its origins.

There are relatively few occasions in his career where Brahms created cyclic instrumental works in this "strict" sense. Perhaps the most renowned is the Third Symphony, where the opening theme reappears, transformed-really transfigured-at the very end of the finale. At the opening of the symphony, the theme is declared boldly and dramatically by the strings; at the end, as it emerges from the finale's main motive, the theme is dissolved by the strings into a gentle fluttering (Ex. 1). Because this work is so familiar, we may not appreciate sufficiently Brahms's inspiration and skill at altering a dynamic, open-ended theme into one that is convincingly cadential. The $F$ on the downbeats of measures 4 and 6 is harmonized in a fashion as remote from a tonic cadence as imaginable; it is underpinned by the surging main motive of the first movement, $\mathrm{F}-\mathrm{A} b-\mathrm{F}$. When the motive is absent, in the return of measures 305 and 307 of the finale, the same melodic $F$ is accompanied by a tonic chord that is fully at rest.

Some commentators have suggested that the cyclic return in the Third Symphony shows similarity to the practices of composers associated with the New German School, including Berlioz, Liszt, and Raff. Brahms is said to be seeking to beat them at their own game. ${ }^{8}$ Whatever his actual motivation, in the Third Symphony Brahms does something

6 Other aspects of cyclic form and thematic transformation in Brahms's early piano sonatas are discussed in my Brahms and the Principle of Developing Variation (Berkeley: Univ. of California Press, 1984), chap. 2. See also Kip J. Montgomery, "Cyclic Form in the Music of Brahms" (Ph.D. diss., State U niv. of New York at Stony Brook, 2002), 88- 108.

7 Letter of 17 Sept. 1894, repr. and trans. in Johannes Brahms: Life and Letters, ed. Styra Avins (Oxford: O xford U niv. Press, 1997), 722.

8 A. Peter Brown, "Brahms' Third Symphony and the New German School," Journal of M usicology 2 (1983): 434-52; David Brodbeck, "Brahms, the Third Symphony, and the New German School," in Brahms and $\mathrm{H}$ is World, ed. Walter Frisch (Princeton: Princeton Univ. Press, 1990), 65-80. 
ex a mpl e 1. Brahms, Symphony No. 3

a. i, mm. 1-4
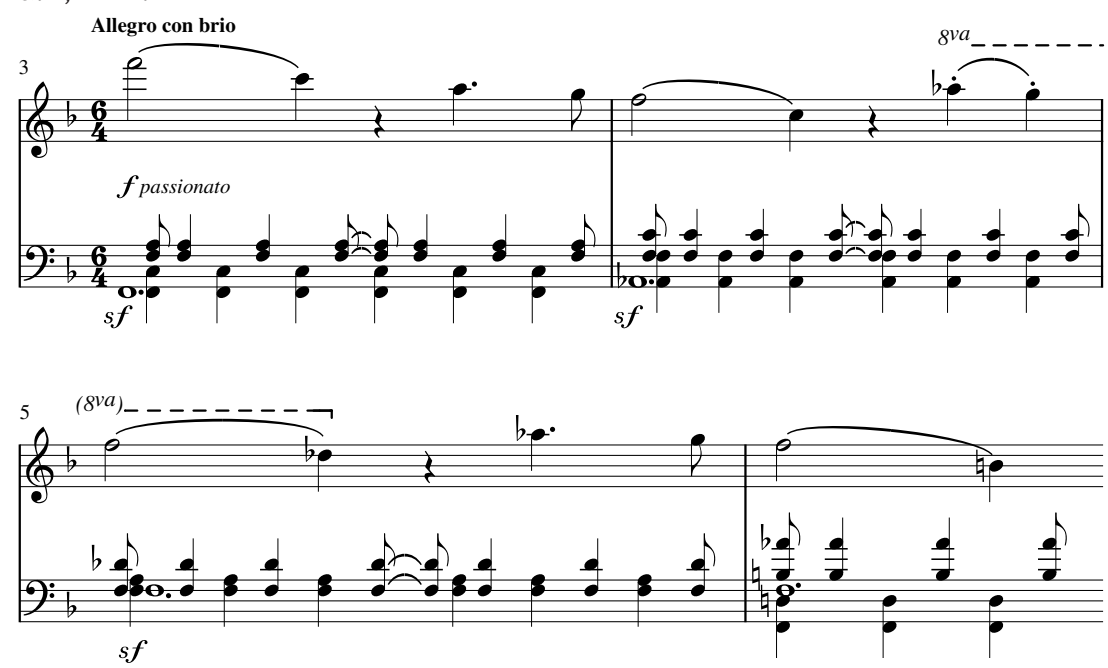

b. iv, mm. 301-5

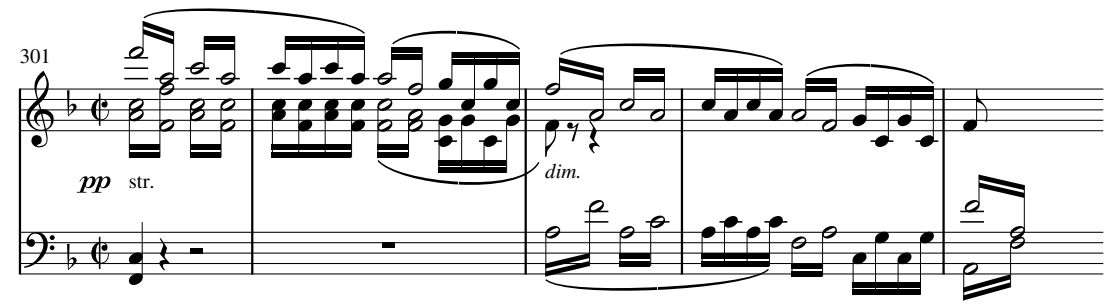

rather different from his contemporaries. The transformation of the main theme at the end is not so much a return to where we started as it is an emblem of how far we have come. It marks the endpoint of thematic, harmonic, metrical, and formal processes that span the entire symphony. These processes-including a conflict between the pitches $A_{\sharp}$ and $A b$ and between meters of ${ }_{4}^{\mathbf{6}}$ and $\underset{2}{\mathbf{3}}$-are set in motion by the first theme and are resolved only in its final appearance.

In this way, Brahms's cyclic processes in the Third Symphony are really part of a larger process of development, a kind of developing variation on the broadest scale. ${ }^{9}$ In this lies a difference between Brahms

9 See my discussion of these aspects of the Third Symphony in Brahms: The Four Symphonies (New Haven: Yale Univ. Press, 2003), chap. 5. 
and other composers of cyclic works in the latter part of the 19th century. One might say, paraphrasing that old Smith Barney television ad with John Houseman: Brahms achieves his cyclic returns the oldfashioned way; he earns them.

Two other large-scale works of Brahms that use cyclic processes in a similar way to the Third Symphony are the German Requiem, op. 45, and the Schicksalslied, op. 54. In the Requiem, elements from the opening movement return in the final movement, where, as in the Third Symphony, they seem to grow almost imperceptibly out of the thematic material. As in the symphony, the recurrence seems less a return to a point of origin than the marker of a long spiritual and musical journey undertaken across the work. The parallel Biblical texts chosen by Brahms are integral to the cyclic process: "Selig sind, die da Leid tragen" in the first movement becomes "Selig sind die Toten die in den Herrn sterben" in the last. ${ }^{10}$

The Schicksalslied is perhaps Brahms's most overtly cyclic work. The entire opening orchestral introduction returns to conclude the piece. But even here, the return is not literal: Details of the orchestration are changed, and more importantly, the section is transposed from its original key, $E b$, to $C$ major. The new key reflects, among other things, a resolution of the preceding turbulent section in C minor. As John Daverio pointed out in an important article, Brahms's cyclic procedures in the Schicksalslied seem to capture a fundamental literary principle, the "Wechsel der Töne," or "alternation of tones," held by Hölderlin, the author of the text. ${ }^{11}$ According to this principle, a work will be shaped as a succession of poetic tones or moods, of which the basic ones are the naïve, the heroic, and the ideal.

The poem of Schicksalslied contrasts the apparently tranquil, carefree life of the Greek gods with the anguished, troubled existence of humans. Daverio argues that across its three stanzas the text moves from the naïve tone, through the ideal, to the heroic. In his setting, Brahms expands this progression with his postlude, returning to the ideal realm. Rather than a literal return, the postlude "imparts an open-ended, spiral shape to the whole." Daverio elaborates: "Holderlin's progression ... supplied the basis for alterations-slight but significant-in Brahms's scheme, whose ostensible return to its naïve starting point in fact marks a turn into the ideal, reflective realm of self-knowledge."12 As in the

10 The rich and complex cyclic procedures of the Requiem are well treated by Montgomery, 154-95, who is right to note that for all the literature on the Requiem, "the work's cyclic structure has not been satisfactorily analyzed" (155).

11 John Daverio, "The Wechsel der Töne in Brahms's Schicksalslied," Journal of the American Musicological Society 46 (1993): 84-113.

12 Ibid., 107-8. 


\section{thejournal of musicology}

Third Symphony and Requiem, then, the end of the Schicksalslied represents less a return to a point of origin, in Macdonald's phrase, than a closure in a different place associated with that point of origin.

To summarize, then: Brahms's cyclical processes never give the impression of mere recollection or return. They confirm a distance traveled, a journey completed. They acknowledge that in music, as in life, time implies-indeed, creates-distance and transformation. Music must use its own language and techniques to represent that process.

\section{III}

With these issues in mind, let us turn to Brahms's third, and last, string quartet, op. 67 in Bb. It was composed in 1875, in the shadow of the First Symphony. After completing the $\mathrm{H}$ aydn Variations in 1873 , his first large-scale orchestral work in many years, Brahms began to resurrect his work on the symphony, which had been gestating for over 13 years, since 1862. In the summer of 1875 Brahms seems to have been at work on the finale, but set it aside to busy himself, as he put it, with "quite useless things-so as not to look a somber symphony in the face."13 One of the "useless things" was the Third Quartet in B b. Only a year later, in the summer of 1876 was Brahms to bring the First Symphony to completion.

It is tempting to see the quartet as a kind of mini-laboratory for the techniques Brahms was working out in his First Symphony. Certainly, both works are retrospective. The First Symphony, as is often pointed out, seems to carry within it, or perhaps upon it, the weight of the entire tradition of the genre from $\mathrm{H}$ aydn through Schumann. The quartet wears its past more lightly; we might indeed speak of a neo-classical approach.

The opening theme of Brahms's B $b$ Q uartet clearly evokes M ozart's "H unt" Q uartet, K. 458, with which it shares a key, meter, a basic tempo, and themes presented in two voices, based on triadic horn calls (Exs. 2 and 3). Mozart builds his theme as an antecedent-consequent structure, a standard opening gambit for the classical period. Brahms complicates or dismantles that scheme by fashioning his main theme from a succession of smaller two-measure units, each of which is given a varied repetition. The structure is thus more open-ended ( $a a^{\prime} b b^{\prime} c c^{\prime} d d^{\prime}$ e $\left.e^{\prime}\right)$, and it comprises an uneven 21 measures. All the two-measure units until the last one are self-contained-thus $10 \times 2$. In order to bring the group to a close, Brahms adds a cadence to $B b$ to the final two-measure group, e', in measure 21 , thus creating the asymmetry. The first group

13 Letter of July 1875, in Brahms: Life and L etters, 480. 
ex a mpl e 2. Mozart, "H unt" Quartet, K. 458
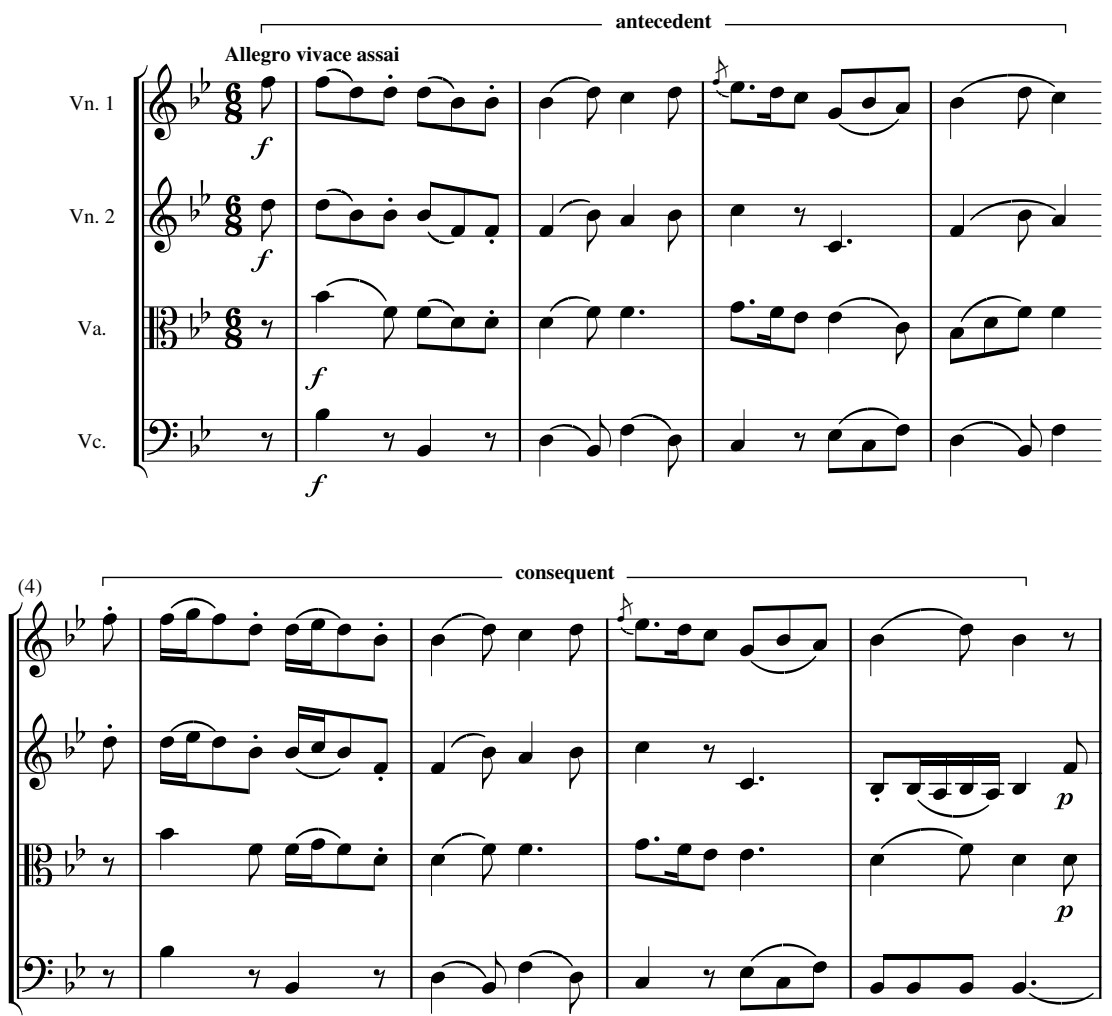

of the first movement of the $B b$ Q uartet is a wonderful example-and as such sets the tone for the entire piece- of how Brahms can be both complex and elegant at the same time.

The finale is cast in Brahms's beloved theme and variations form, which he used many times across his career, not only in independent works, but also within multi-movement works. Brahms wrote a finale in theme and variations form on four occasions: in this quartet, in the Fourth Symphony, and lastly in two of the late clarinet works, the Quintet, op. 115, and the Second Sonata, op. 120, no. 2 in Eb. ${ }^{14}$

In each of these cases, Brahms engineers the theme and variations form, so to speak, to create some kind of cyclic experience. In the case of the Fourth Symphony, as Schoenberg and many since have observed,

14 An excellent assessment of Brahms's variation movements is Elaine Sisman, "Brahms and the Variation Canon," in 19th-Century M usic 14 (1990): 132-53. 
the journal of musicology

ex a mpl e 3. Brahms, Bb Quartet, Op. 67, I, main theme ("horn call")
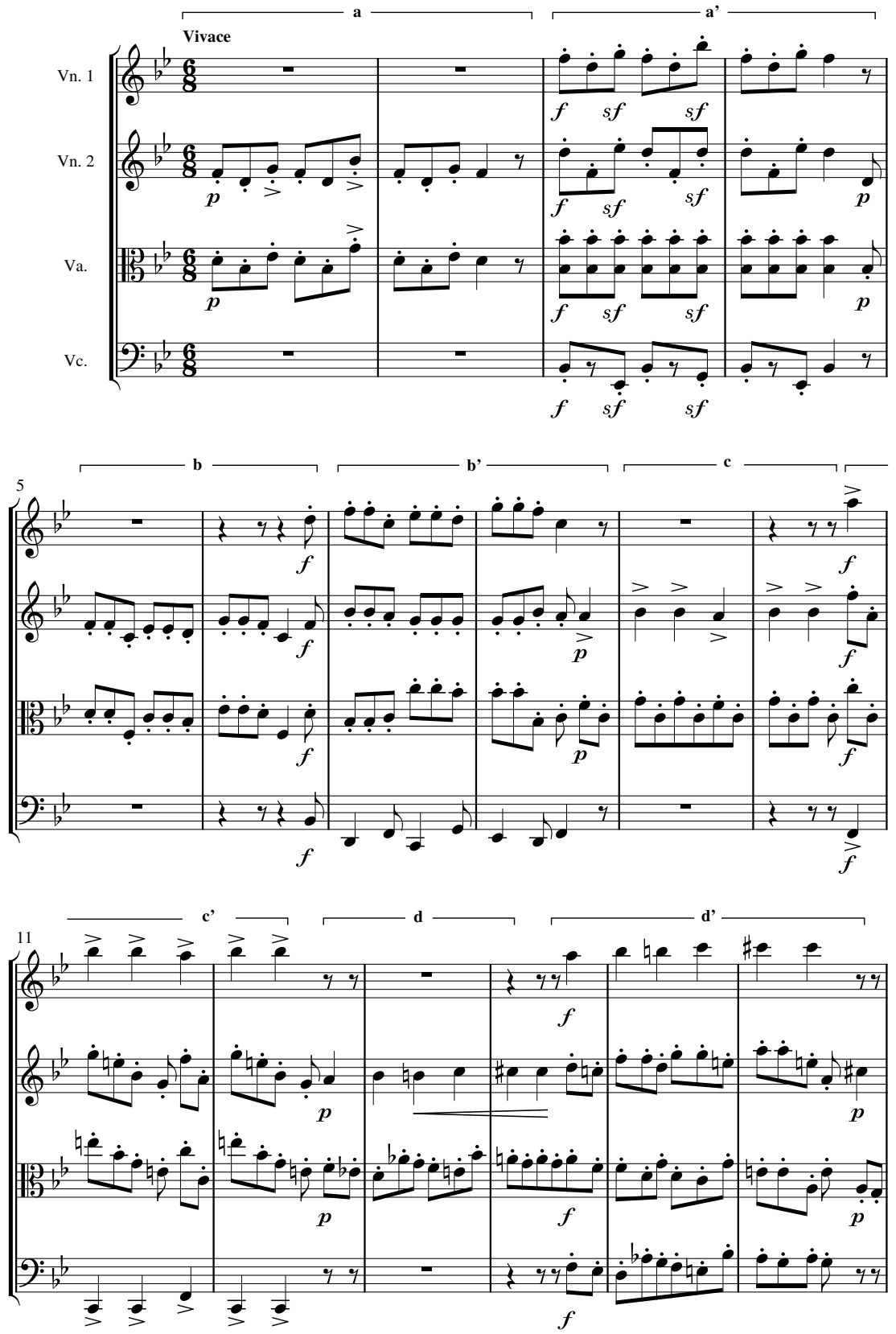
example 3. (continued)
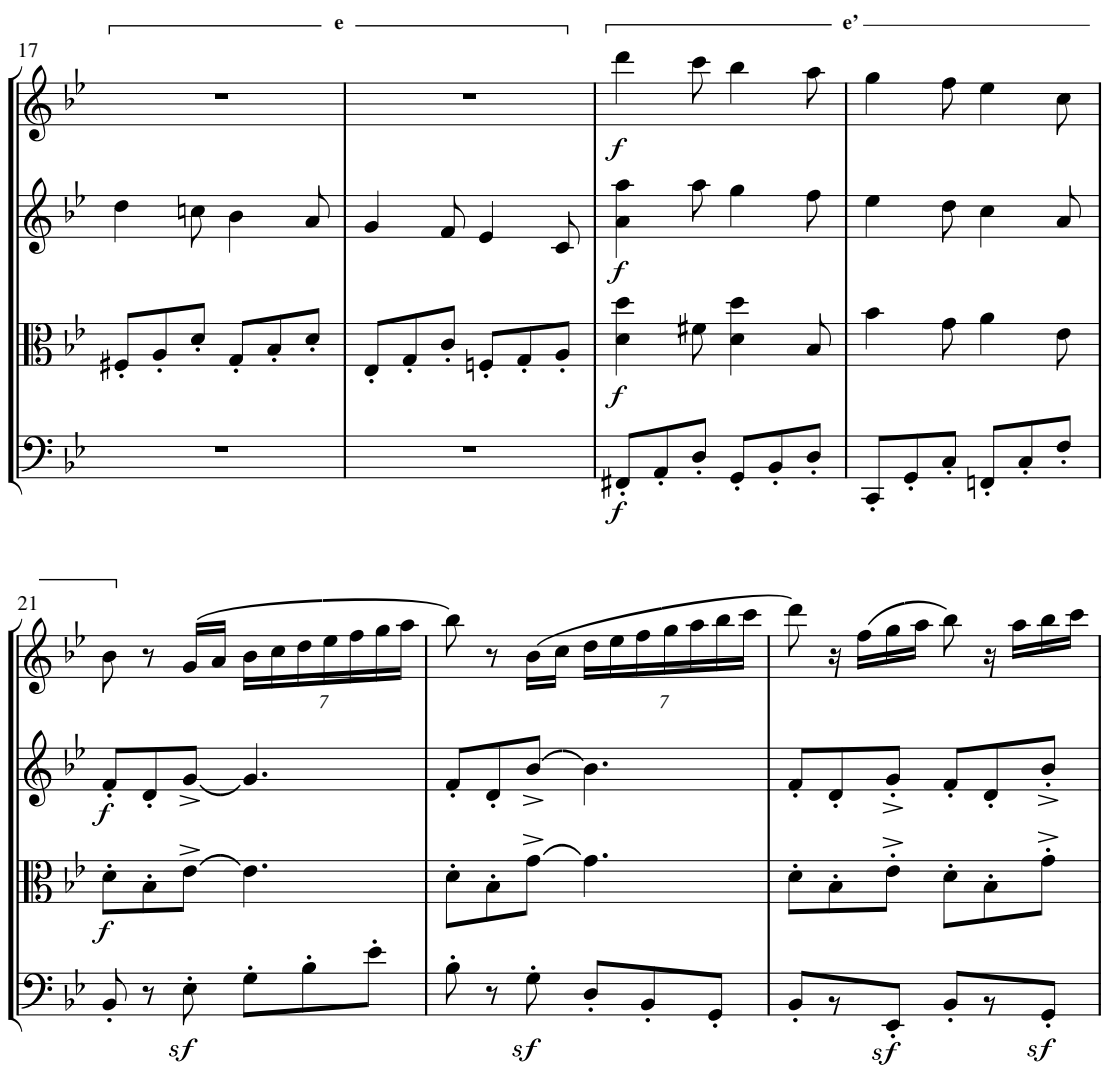

the final variations make an explicit connection to the chain of descending thirds that shapes the opening theme of the symphony. The connection is at once surprising and logical: surprising because the theme itself, a chaconne, rises in a linear fashion, giving no hint of how it might underpin or generate a chain of descending thirds; logical because once Brahms makes the association in variations 29 and 30, the bass line and the thirds fit together perfectly.

In the $\mathrm{B} b$ Quartet, the process is different. First, the finale theme is itself more of a traditional melody-plus-accompaniment than in the Fourth Symphony. Second, unlike the Fourth Symphony, the recollections might be said to invade, rather than infiltrate, the structure, from variation 7 on. Table 1 presents an outline of the movement that can aid our examination. 
the journal of musicology

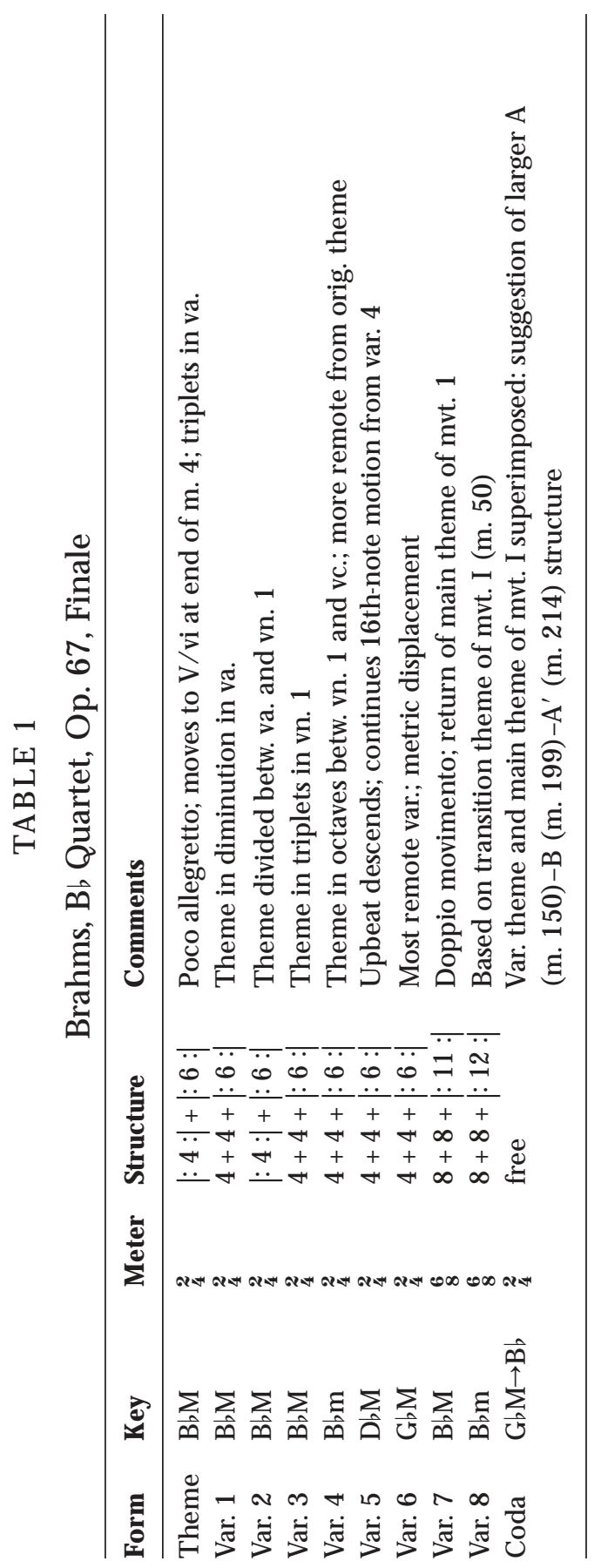


The finale of op. 67 consists of the theme, eight variations, and a coda. The theme itself has two repeated units of four and six measures respectively (Ex. 4). The form is essentially rounded binary, $A B A^{\prime}$, in which $B$ forms a mini-development section beginning on $V / v$, where the $A$ has cadenced. O ne striking aspect of the return in $A^{\prime}$, at least to my ear, is how brief and up-in-the-air it is. In fact $A^{\prime}$ replicates, with some changes, the first two measures of $A$, which in themselves had seemed tentative, in need of continuation, a kind of antecedent to the consequent of measures $3-4$. The tentative quality of $A^{\prime}$ is reinforced by its cadential patterns: $\mathrm{V}-\mathrm{I}$, then a plagal IV-I. It is as though $\mathrm{A}^{\prime}$ picks up from the cadence of $A(\mathrm{~m} .3)$ and then extends it with a less emphatic plagal version.

As can be seen from Table 1, all variations retain the basic structure of the theme: $4+6$ measures. In some the repeats are exact, in some, varied. The first three variations remain fairly close to the original theme in melodic shape and affect, and in key. In variation 4, the key changes to $\mathrm{B} b$ minor, and the theme dissolves in the serpentine figuration played at the distance of two octaves between violin 1 and cello. Brahms also restructures the harmony. Instead of moving to $\mathrm{V} / \mathrm{vi}$ at the end of $A$, he goes to V/III and III, or D b.

The $\mathrm{D} b$ harmony and the end of variation 4 open the gates further to the flat side, which is explored by the succeeding two variations. $\mathrm{Har}$ monically, thematically, and metrically, they become more remote from the original theme. In variation 6 Brahms allies metrical remoteness with harmonic and thematic distance (Ex. 5). The variation unfolds in a 2 meter that is seems to be displaced by an eighth note; because the notated downbeat has been tied over the bar line, the notated upbeat comes to feel like a downbeat of $a_{4}^{2}$ measure. O nly at the start of variation 7 do the notated and implied meters align themselves, when Brahms restores the real upbeat with the fortissimo $\mathrm{F}^{7}$ chord, leading to the tonic on the downbeat of measure 95 (Ex. 6).

Thematically, variation 6 is no less extraordinary. Brahms manages to separate elements of the theme and treat them independently and contrapuntally. He detaches the upbeat and first note of the theme from the main part, the ascending fourth. The upbeat figure appears in the cello, the fourth in the viola and first violin. The cello part almost resembles one of those figure-ground optical illusions-here translated into the aural sphere. If played alone, the cello part seems to support the notated meter; it refers to the original theme, with which we are now familiar and in which strong accents fall on the downbeats. But when played with the upper parts, the cello adapts to their metrically displaced framework. The cello's $\mathrm{F}$ h on the second notated beat of measure 84 is particularly striking in this regard. In its "normal" form, 
the journal of musicology

ex a mpl e 4. Brahms, Bb Quartet, Op. 67, IV, theme
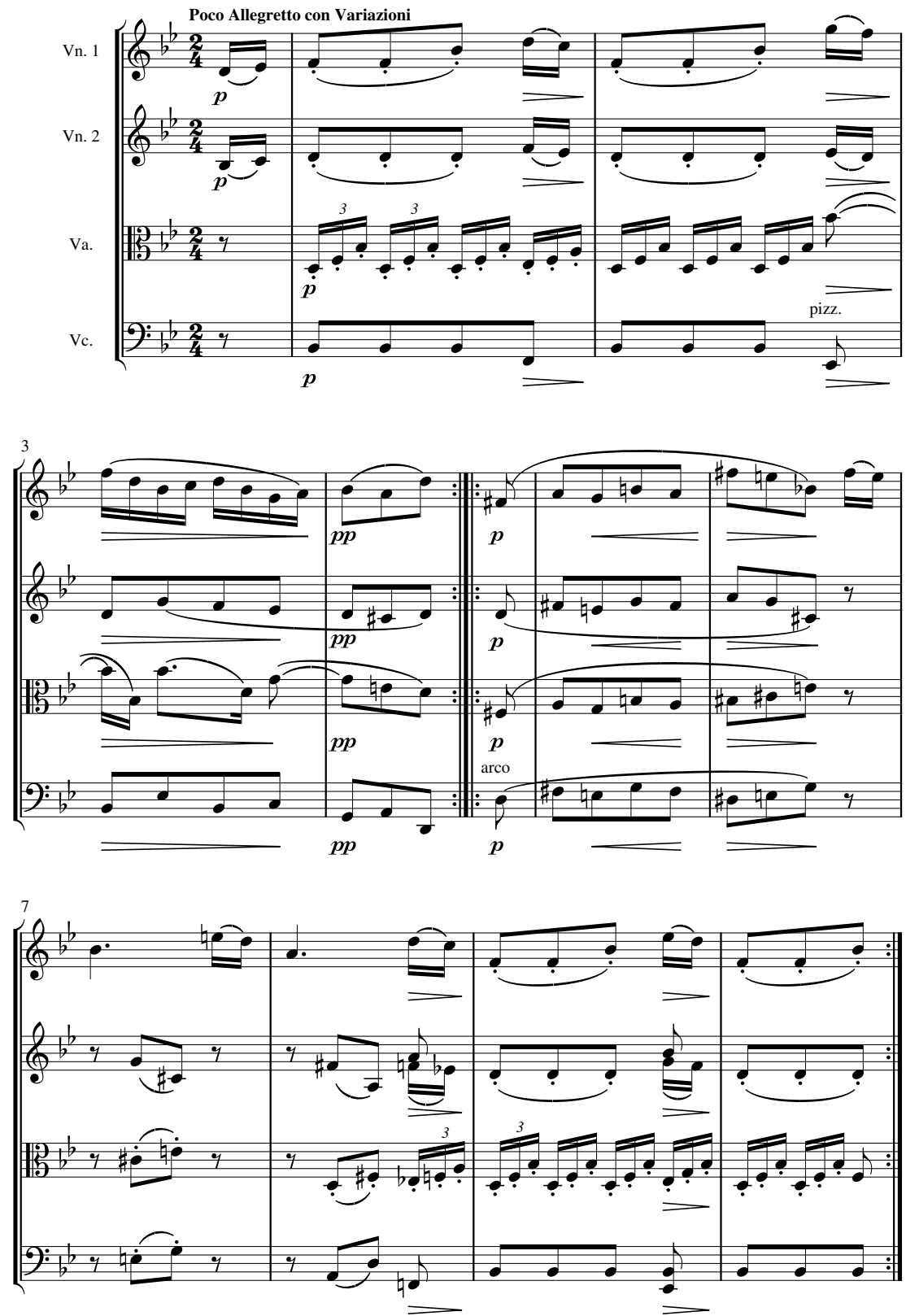
ex a mpl e 5. Brahms, Bb Quartet, Op. 67, IV, var. 6

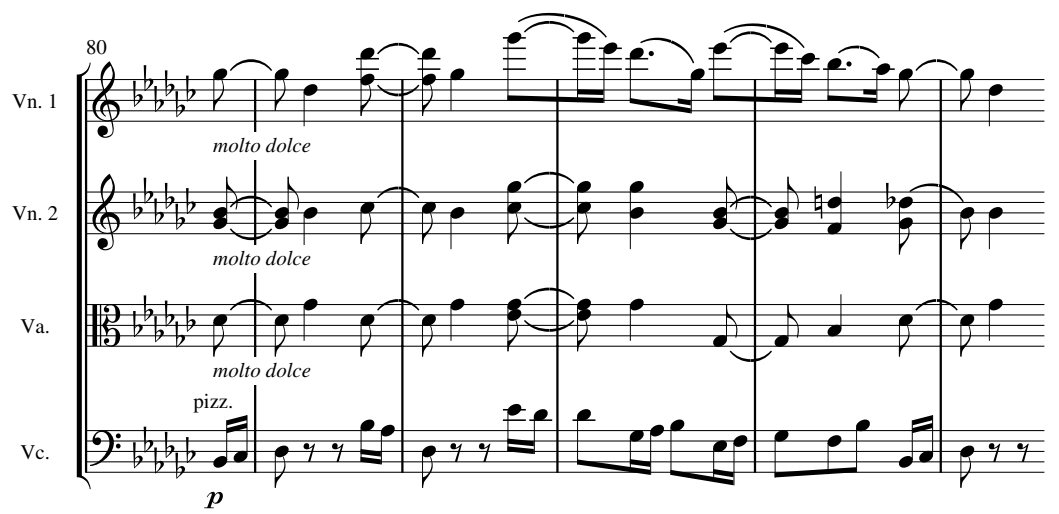

ex a mpl e 6. Brahms, Bb Quartet, Op. 67, IV, var. 7

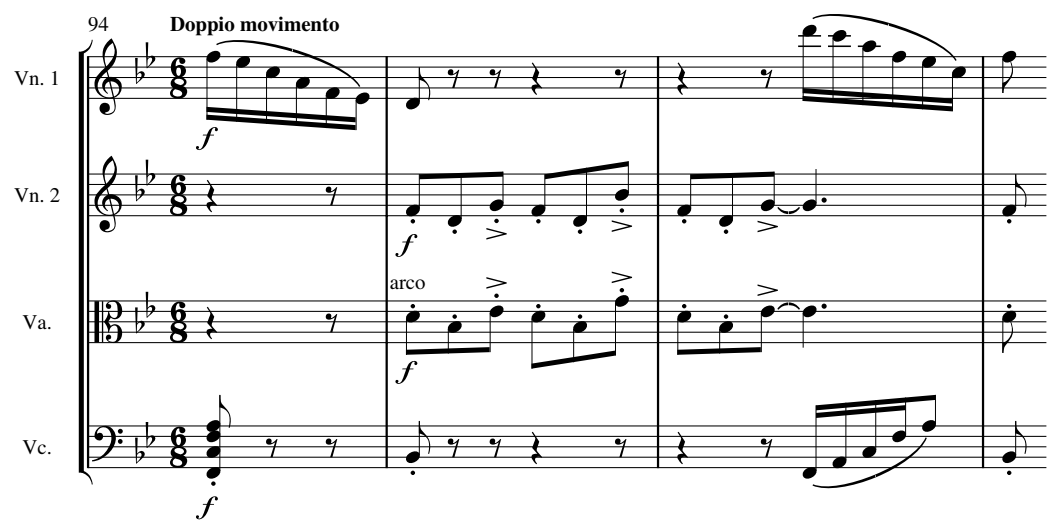

the $F$ would, by analogy to the melodic $A$ a in measure 4 of the theme, support a V/V/ vi chord ( $\mathrm{F}^{7}$ in this context). But because of its placement in the bass, not the melody, and its coinciding with the a displaced strong beat, the $\mathrm{F} \sharp$ in variation 6 has an entirely different profile. It underpins a $\mathrm{B}$ b chord, or III in the context of $\mathrm{G}$ b major.

It is almost impossible to put into words the disorienting quality of this moment. What we can say is that it reflects Brahms's imaginative exploration of musical "space"-up/ down and left/ right. What was above before (in the melody) is now below (in the bass). What was a weak beat in the original theme is now strong. This is the kind of variation, at once beautiful and brainy, that only Brahms could write. 
The biggest surprise at the beginning of variation 7 is not the sudden metrical and harmonic realignment, but the fact that we return to the main theme of the first movement, which I will call the horn-call theme for convenience (Ex. 6). This theme is assimilated into the variations structure of $8+12$ measures ( 11 here, because of a compression, such that B effectively starts on the second half of m. 110). Brahms also adapts the horn-call theme to the harmonic scheme of the variations theme; it moves to V/ vi at the end of the A section.

Although the reappearance of the horn-call theme is surprising, it also feels appropriate. This is in part because Brahms has created the variations theme out of the basic skeleton of the horn-call theme (Ex. 7). The rising fourth $\mathrm{F}-\mathrm{B} b$ is prominent in both themes, as are the harmonies vi and V/ vi (in e of the horn-call theme). By also building the basic rhythmic figure of his variations theme as a three-eighth-note unit grouped within one slur, Brahms invites us to make the association back to the horn-call theme, despite the different meter. To my ear, the contour of three-note motive $B,-A-C$, the final gesture of $A$ in the variations theme, clearly recalls the initial figure of the horn call, F-D-G.

Thus variation 7, for all its shock value, becomes integrated into the structure of the finale. But more surprises are in store. Brahms bases the final variation, no. 8, on another part of the first movement, the transition theme of the exposition, which is likewise fitted to the $8+$ 12 measure structure of the variations. Of course, this transition theme itself is derived from the main theme; its second measure is a legato rendering of the horn calls in minor. As in variation 4 , the other minor variation, Brahms modulates in $\mathrm{A}$ from $\mathrm{i}$ to $\mathrm{III}$, or $\mathrm{D} b$.

In the second ending of $A^{\prime}$ in var. 8, however, Brahms stages another surprise. A deceptive move to $\mathrm{G}^{7}$ (the $F$ is held over in the viola from the previous measure) freezes all harmonic, thematic, and rhythmic motion, and leads us into the coda. We return to the variations theme and $\underset{\mathbf{4}}{\mathbf{2}}$ meter, now renotated to accommodate the "doppio movimento" in force since variation 7 . The start of the coda remains in a very remote harmonic region - the same $\mathrm{G} b$ major reached in variation 6 . At this moment, with the movement suspended in $\mathrm{G} b$, Brahms creates the epiphany that lies at the heart of the cyclic processes in this quartet. He superimposes the variations theme and the horn-call theme from which it was derived, immediately making clear the kinship between the two. The confirmation, or we might say celebration, of this thematic relationship is the goal of the remarkable coda.

At the beginning of the coda, the triplets of the horn-call theme are played legato, grouped under a single slur (Ex. 8a). The horn call is 
ex a mpl e 7. Relationship between horn-call theme and variations theme in Brahms's B b Q uartet, O p. 67

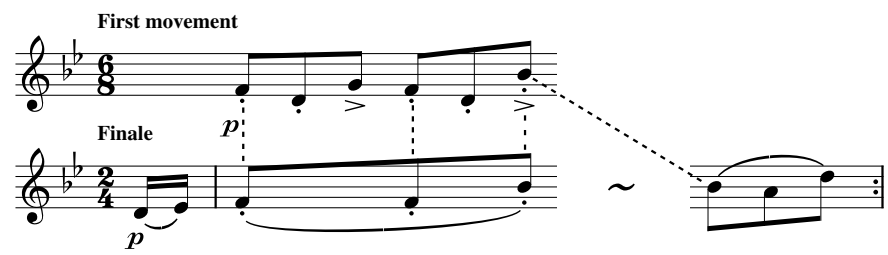

thus out of character; it is assimilated to the gentle lilt of the variations theme. At the return to the tonic in measure 183, Brahms reverses the arrangement: both themes are now forte and staccato-thus the variations theme is adapted to the original mood of the horn-call theme (Ex. 8b).

In their final appearance together, beginning in measure 213, the variations and horn-call theme at last return to their original characters (Ex. 8c). The variations theme is marked dolce. In measure 150, at the start of the coda, the dolce had been applied by Brahms to all four parts. Now, significantly, only the first violin is dolce. Beneath it the horn call appears for the first time in the coda in its initial two-voice form between violin 2 and viola, staccato. It is hard to envision a more satisfying conclusion to the movement, and to the work.

O ne other epiphany, though a more subtle one, occurs in the coda. In measure 198, just before the last appearances of both themes, Brahms revisits the B part of the variations theme (Ex. 9a). (This B may be said to make the coda into a very large and free variation, as suggested by the comment on Table 1.) As it did in the theme, B moves harmonically to $\mathrm{V} / \mathrm{vi}$, which is here sustained in first inversion, with an $\mathrm{F} \#$ in the bass, across three and a half measures (mm. 210-13; Ex. $9 \mathrm{~b}$ ). On the second beat of measure 213 , the $F \#$ (in the viola) moves down to the dominant $\mathrm{F}$, which supports a $\mathrm{V}^{7}$ chord. At this moment we realize that throughout the movement Brahms has been exploring the implications of the enharmonic equivalence between $\mathrm{G} b$ and $\mathrm{F} \#$. This passage is analogous to that which led into the coda at measure 150, where the variations and horn-call theme emerged over a Gb pedal (the flatted-sixth degree in $\mathrm{B} b$ major). At the start of the coda, Brahms avoids its normal resolution, down a half step to the dominant. O nly at measure 213 does he provide the expected resolution; and here the dominant arrives not from a chord based on $\mathrm{G} b$, but from the $\mathrm{V}^{6} / \mathrm{iii}$ chord over $F \#$. In a strict sense, then, the $F \#$ resolves incorrectly, moving down to $\mathrm{F}$ q rather than up to $\mathrm{G}$ q. This "wrong" resolution is Brahms's final surprise in this very surprising coda movement. 
the journal of musicology

exampl e 8. Brahms, Bb Quartet, Op. 67, IV, Coda

a.

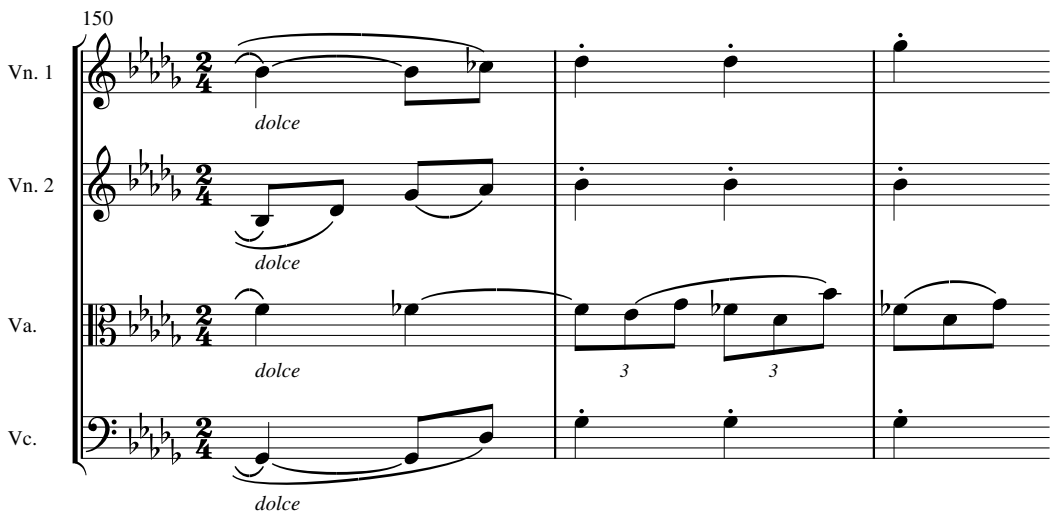

b.

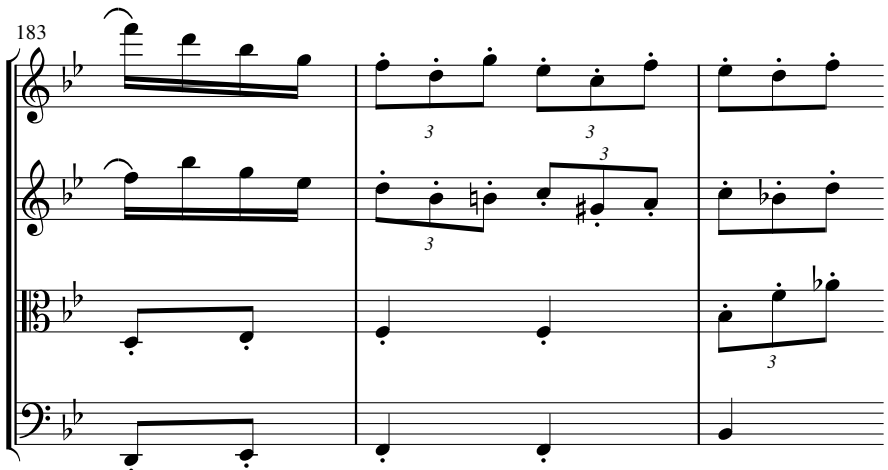

C.

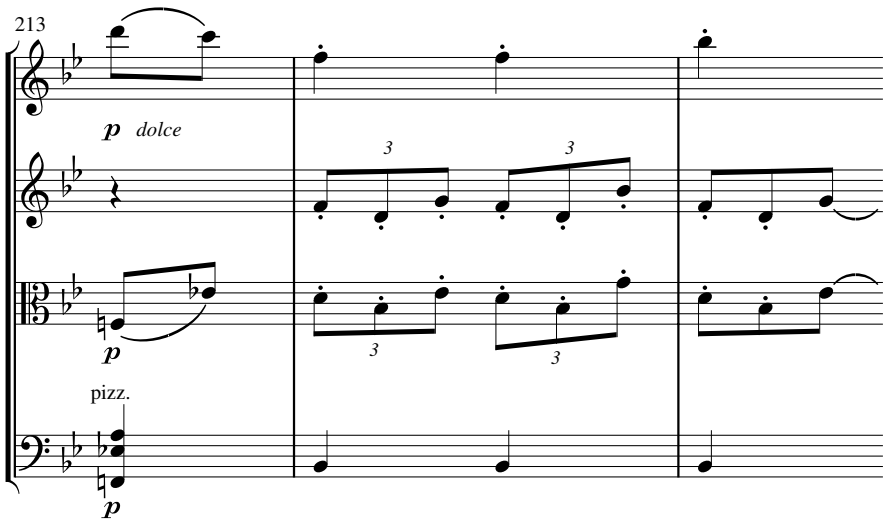


exampl e 9. Brahms, Bb Quartet, Op. 67, IV, Coda

a.

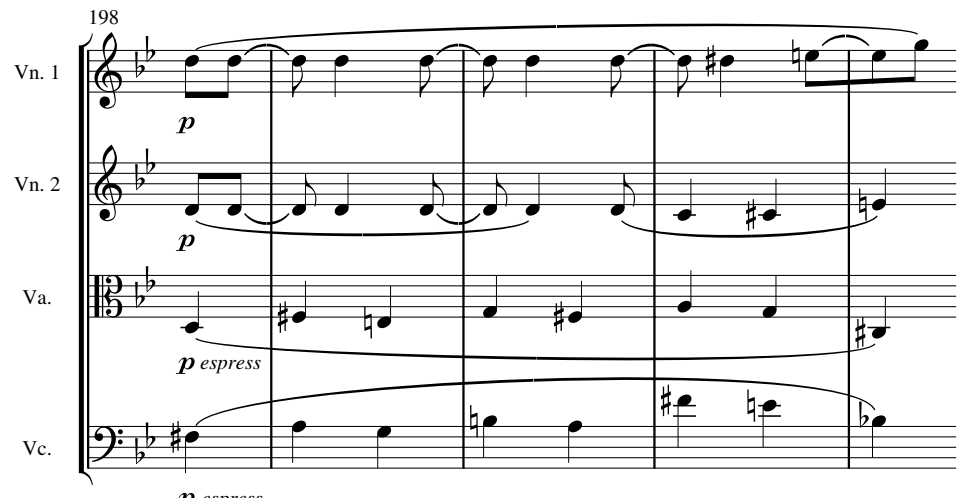

$\boldsymbol{p}$ espress

b.

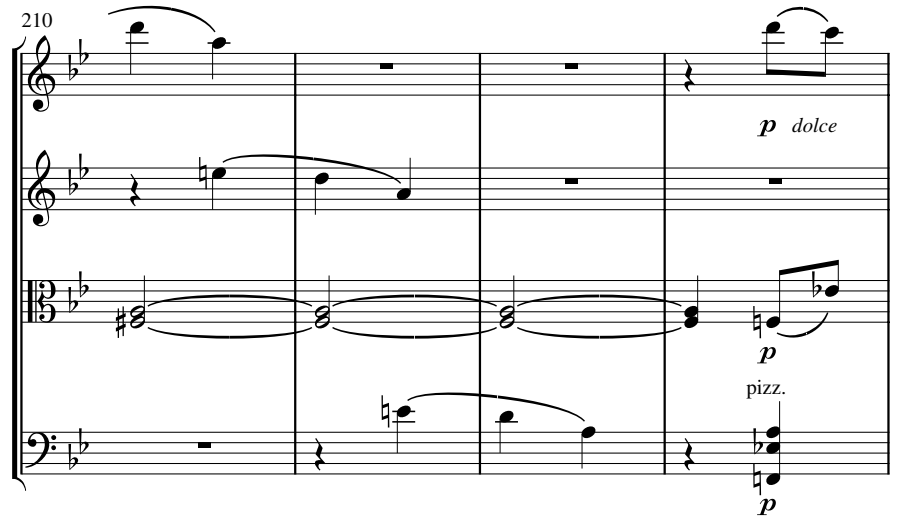

Brahms's cyclic procedure here differs from that which he would explore in the Third Symphony. In the later work, the main theme is greatly transformed at its reappearance, and the transformation marks the end of an expressive journey taken. In the quartet, Brahms brings back the opening theme of the work in its original form. It arrives, in measure 95 of the finale, as a surprise-the shock of the old-when we are expecting a further variation of the finale's theme. Unlike in the Third Symphony, the sudden return of the horn-call theme seems to thrust us back in time, to the start of the quartet. Yet Brahms also is saying that no real return is possible. The surprise of measure 95 forces 


\section{thejournal of musicology}

the listener to wonder whether there is some connection-a connection he or she may have missed-between the horn-call theme and the variation theme.

Across the coda, Brahms sets about answering that question in the affirmative. While respecting the differences in character between the two themes, he manages in the end to reconcile them. Some might say that Brahms works too hard to achieve cyclic closure-he ties up harmonic, thematic, and rhythmic loose ends very neatly. Yet in the $\mathrm{B}$ b Quartet, unlike in some other works of Brahms, the ratio between effort and result seems just about ideal. Nowhere in the 19th century is cyclic form handled with a more satisfying balance between technique and inspiration.

Columbia University

\section{ABSTRACT}

Brahms's Third String Quartet, op. 67 in Bb Major, represents one of his greatest efforts in cyclical form, but has been neglected in the analytical and critical literature, which has focused on the Third Symphony, the Schicksalslied, and the German Requiem. Brahms's cyclic techniques fall between the procedures of Beethoven, who aims for thematic unity or coherence across a work, and French composers at the end of the 19th century, who use extensive, intricate thematic transformation to bind a piece.

Brahms designs the finale of his $B b$ Quartet, a theme and variations, to evolve toward the reappearance of the main thematic material of the first movement. In the coda of the finale, the themes of the two outer movements are superimposed in ways that reveal their latent kinship. 
Reproduced with permission of the copyright owner. Further reproduction prohibited without permission. 